\title{
THE SIMULATION AND EXPERIMENTAL RESULTS OF DYNAMIC BEHAVIOUR OF TORQUE MOTOR HAVING PERMANENT MAGNETS
}

\author{
Željko Despotović ${ }^{*}$ - Vladimir Šinik ${ }^{* *}$
}

\begin{abstract}
The application, construction, and principle of operation of the torque motor having permanent magnets are presented first. Since dynamic behaviour of a servohydraulic system is, to a large extent, determined by dynamic behaviour of the applied torque motor, an analysis of motor's dynamic behaviour is carried out and its dynamic transfer characteristic is determined. Finally, the simulation and experimental results of dynamic behaviour of the torque motor are presented.
\end{abstract}

K e y w or ds: torque motor, permanent magnet, servo valve, dynamic model, simulation

\section{INTRODUCTION}

The most frequently applied electrically controlled hydraulic preamplifier is servovalve. Within servovalve an electric input signal is converted to a shift, or move, of a pilot piston, which is via a hydraulic amplifier converted to a hydraulic variable, usually flow or pressure. As a converter of the small current (or voltage) signal to mechanical movement, usually a controlled motor called torque motor is used.

Torque motor may produce a rotational or linear movement, where the developed torque, or force, is proportional to input current, [1].

In majority of servohydraulic valves the torque motor is an independent device. It is mounted separately ans is hermetically sealed against the hydraulic part (operating fluid). The torque motor consists of the windings positioned across anchor to provide its magnetization and permanent magnets which, together with polar extensions, consitute magnetic circuit of the armature.

By low power control signals (of the order $10 \mathrm{mV}$ ) one can control powers as large as several hundreds od kilowats. A mulitude of papers has been devoted to the control of hydraulic systems, their modeling, and improvement of their performance [1-16]. Dynamic behaviour of a system as a whole is largely, in addition to the hydraulic components, determined by dynamic processes in the torque motor, [5], [11-14]. In the present paper dynamic behaviour of torque motor is analyzed and its transfer characteristic in $s$-domain is determined. By the simulation and experimental results the conclusions of the dynamic analysis have been confirmed and the theoretical mathematical model of the torque motor has been verified.

\section{DYNAMIC MODEL OF TORQUE MOTOR}

The construction, principle of operation, and mathematical model of a torque motor having permanent magnets are given in [1]. If $i$ - total signal current and if the armature windings are identical, current in each of the windings will be $i / 2$. For each of the armature windings (Fig. 1) the following voltage relation applies

$$
E_{0}-R_{0} i=R_{c} \frac{i}{2}+N_{c} \frac{\mathrm{d} \Phi_{a}}{\mathrm{~d} t},
$$

where $E_{0}$ is the output voltage of the amplifier driving the torque motor, $r_{0}$ - amplifier's internal resistance, $R_{c}$ - resistance of each of the windings, $N_{c}$ - number of turns of each of the windings, and $\Phi_{a}$ - total magnetic flux passing through the armature.

Total magnetic flux $\Phi_{a}$ passing through the armature is given by the relation, derived elsewhere, which can be represented as

$$
\Phi_{a}=2 \Phi_{g} \frac{x}{g}+\frac{N_{c}}{\Re_{g}} i
$$

where: $g$ - length of each of the air gaps when the armature is in neutral position, $x$ - shift of armature ends with respect to the neutral position, $\Re_{g}=g / \mu_{0} A_{g}$ - reluctance of each of the air gaps when the armature is in the neutral position, and $\Phi_{g}$ - flux in each of the air gaps when the armature is in the neutral position, [1].

From relations (1) and (2), by applying Laplace transform one obtains

$$
E_{0}=\left(R_{0}+\frac{R_{c}}{2}\right) i(s)+K_{b} s \theta(s)+L_{c} s i(s) .
$$

$K_{b}$ is voltage constant of each of the windings, expressed in $(\mathrm{V} / \mathrm{rad} / \mathrm{s})$, given by relation

$$
K_{b}=2 \frac{a}{g} N_{c} \Phi_{g}
$$

\footnotetext{
* Institute "Mihajlo Pupin", Belgrade, Serbia, ${ }^{* *}$ Technical Faculty "Mihajlo Pupin" Zrenjanin, University of Novi Sad, Serbia, zeljko.despotovic@pupin.rs
} 


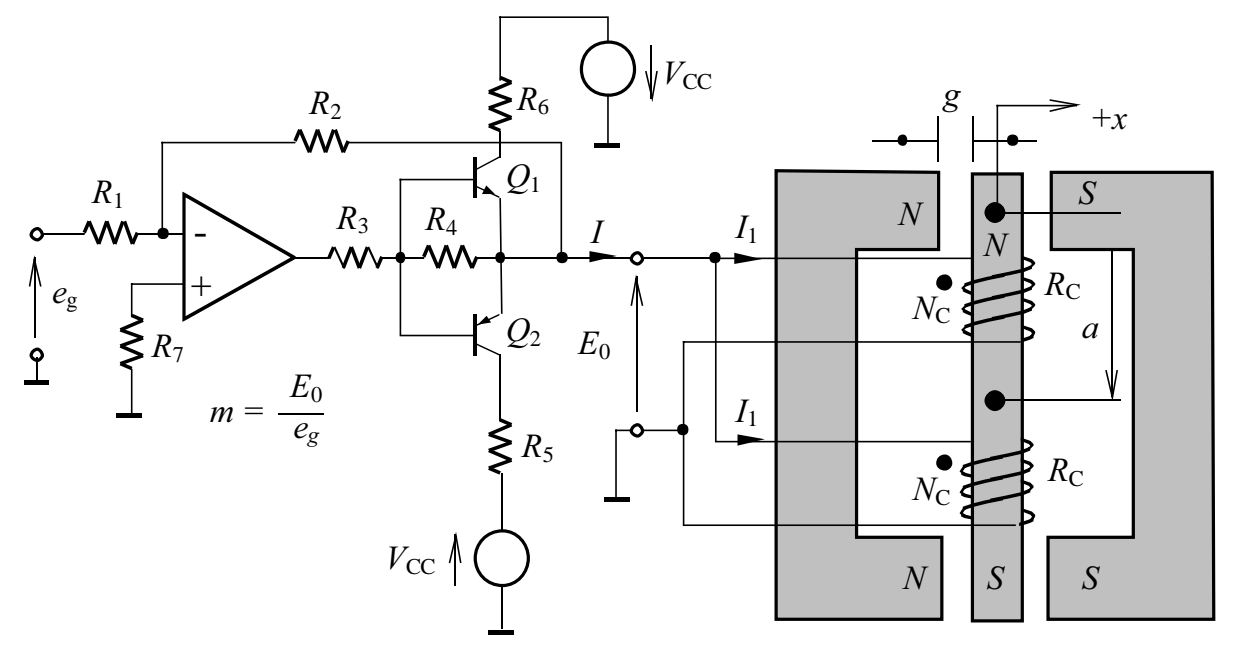

Fig. 1. Wiring diagram of torque motor

$L_{C}$ is self-inductance of each of the windings, given by relation

$$
L_{c}=\frac{N_{c}^{2}}{\Re_{g}} .
$$

The relation for electromagnetic torque of work performed in the vicinity of operating point can be represented as $[3]$

$$
T_{d}=K_{t} i+K_{m} \theta
$$

where: $\theta$ - angle of armature turning, and $a$ - radius from the centre to armature ends, $K_{t}$ is torque constant of the motor in $(\mathrm{Nm} / \mathrm{A})$, given by relation

$$
K_{t}=2 \frac{a}{g} N_{c} \Phi_{g}
$$

and $K_{m}$ is a constant of magnetic elasticity of the motor in $(\mathrm{Nm} / \mathrm{rad})$, given by relation

$$
K_{m}=4\left(\frac{a}{g}\right)^{2} \Re_{g} \Phi_{g}^{2}
$$

By applying the second Newton law, one can write

$$
T_{d}=J_{a} \frac{\mathrm{d}^{2} \theta}{\mathrm{d} t^{2}}+B_{a} \frac{\mathrm{d} \theta}{\mathrm{d} t}+K_{a} \theta+T_{L},
$$

where: $J_{a}$ - inertia of the armature and the attached moving parts, $B_{a}$ - total viscous damping coefficient of the armature, load, and other moving masses, $K_{a}-$ mechanical torsion spring constant of the armature pivot, and $T_{L}$ - moment of load.

By combining (6) and (9) and by applying Laplace transform one obtains

$$
K_{t} i(s)=J_{a} s^{2} \theta(s)+B_{a} s \theta(s)+\left(K_{a}-K_{m}\right) \theta(s)+T_{L} .
$$

Note that magnetic elasticity constant $K_{m}$ has to be smaller than mechanical elasticity constant $K_{a}$ in order that the system is stable. Relations (3) and (10), together with the torque motor parameters defined by (4), (5), (7), and (8) completely describe its dynamic behaviour. The parameters are calculated on the basis of construction data for $\Re_{g}, N_{c}, g, a$, and $\phi_{g}$. Variable $\phi_{g}$ is often expressed as product of flux density $B_{g}$ in the air gap a surface $A_{g}\left(\phi_{g}=B_{g} A_{g}\right)$. It is clear that for the defined parameters

$$
\begin{aligned}
K_{t} & =K_{b}, \\
K_{m} L_{c} & =K_{b} K_{t} .
\end{aligned}
$$

By neglecting mechanical damping $B_{a}$, and by combining (3) and (10) one obtains

$$
\theta(s)=\frac{K_{o} e_{g}(s)-\left(1+\frac{s}{\omega_{a}}\right) T_{L}(s) /\left(K_{a}\left(1-\frac{K_{m}}{K_{a}}\right)\right)}{\left(1-\frac{K_{m}}{K_{a}}\right)^{-1}\left(\frac{s^{3}}{\omega_{a} \omega_{m}^{2}}+\frac{s^{2}}{\omega_{m}^{2}}+\frac{s}{\omega_{a}}\right)+1},
$$

where $K_{o}=\frac{K_{t} \mu}{\left(R_{0}+\frac{R_{c}}{2}\right) K_{a}\left(1-\frac{K_{m}}{K_{a}}\right)}-$ static gain (in $\mathrm{rad} / \mathrm{V})$,

$\omega_{a}=\frac{2 R_{0}+R_{c}}{2 L_{c}}-$ circuit-break frequency of the armature winding $(\mathrm{rad} / \mathrm{s})$,

$\omega_{m}=\sqrt{K_{a} / J_{a}}-$ mechanical natural frequency of the armature (rad/sec),

$e_{g}$ - control voltage at input of the amplifier, and $\mu=E_{0} / e_{g}$ - voltage gain of the amplifier.

If numerical values of the coefficients are known, denominator of relation (13) can be factorized. The coefficients are so related that one can obtain a general form containing roots of the equation, which can be represented graphically. The final equation representing dynamic behaviour of the torque motor having contol voltage $e_{g}$ and load moment $T_{L}$ is

$$
\theta(s)=\frac{K_{o} e_{g}(s)-\left(1+\frac{s}{\omega_{a}}\right) T_{L}(s) /\left(K_{a}\left(1-\frac{K_{m}}{K_{a}}\right)\right)}{\left(1+\frac{s}{\omega_{r}}\right)\left(\frac{s^{2}}{\omega_{o}^{2}}+\frac{2 \delta_{o}}{\omega_{o}} s+1\right)},
$$

where $\omega_{r}, \omega_{o}$, and $\delta_{o}$ as functions of $\omega_{a} / \omega_{m}$ are shown in diagrams of Figs. 2, 3, and 4, respectively. From these 


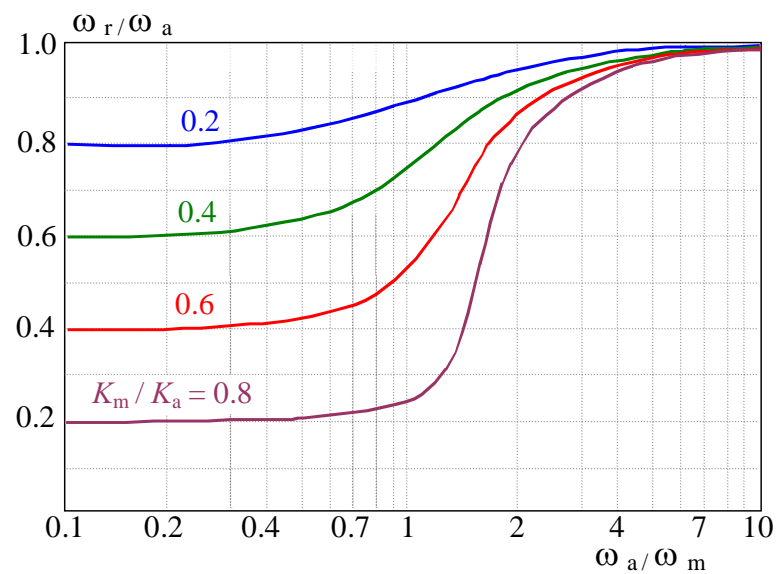

Fig. 2. Normalized diagram of real roots of the torque motor transfer function

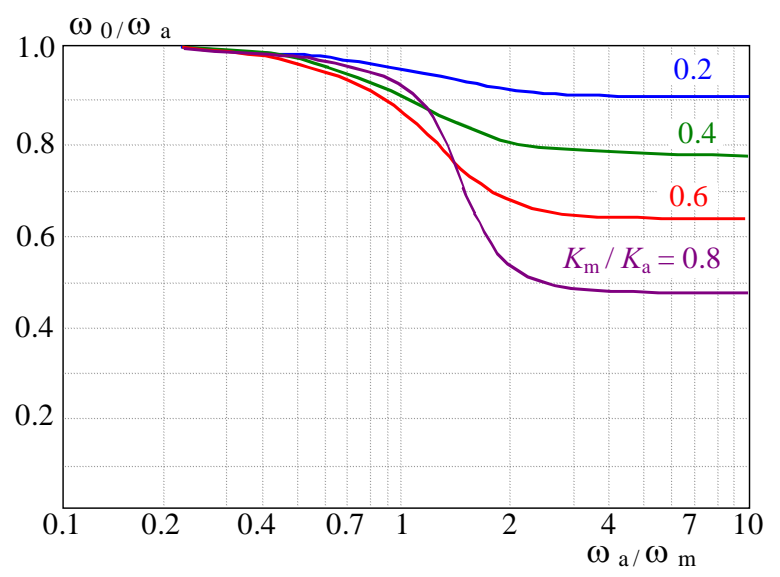

Fig. 3. Normalized curves of the natural frequency of the torque motor

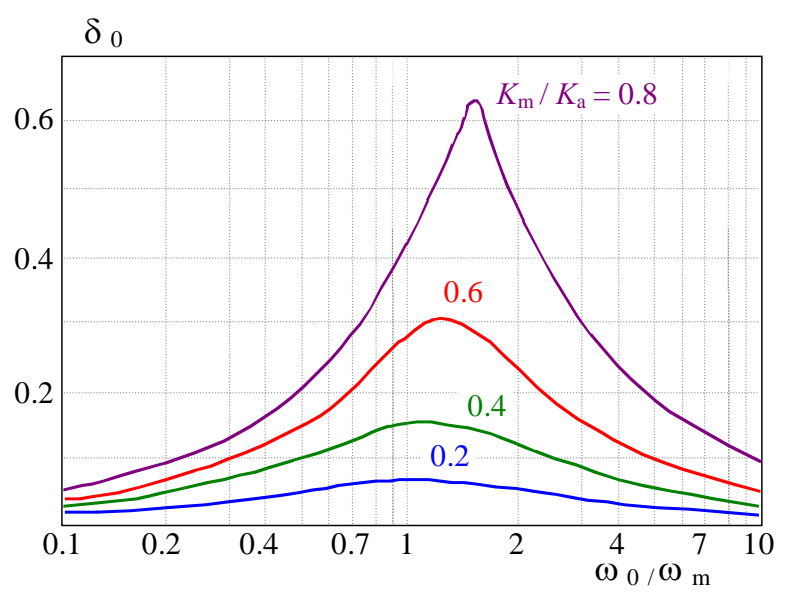

Fig. 4. Plot of damping ratio of the torque motor

diagrams one can see that the third order characteristic equation has one linear and two subattenuating roots. These factors are the consequence of the electric time constant $1 / \omega_{a}$ and mechanical resonance frequency of the armature. However, turning point frequencies of the third order characteristic equation are lower, ie $\omega_{r}<\omega_{a}$ and $\omega_{o}<\omega_{m}$. Since for realized torque motors $K_{m} / K_{a}<$ $1 / 2$, the following approximations are suitable for per- forming the calculations

$$
\omega_{r} \approx \omega_{a}, \quad \omega_{o} \approx \omega_{m}, \quad \delta_{o} \approx \frac{1}{2} \frac{K_{m}}{K_{a}} .
$$

Transfer function of a load-free torque motor with respect to input voltage $e_{g}$ is

$$
\frac{\theta(s)}{e_{g}(s)}=K_{o}\left(1+\frac{s}{\omega_{r}}\right)^{-1}\left(\frac{s^{2}}{\omega_{o}^{2}}+\frac{2 \delta_{o}}{\omega_{o}} s+1\right)^{-1}
$$

Usually this transfer function is given with respect to control current $i(s)$ in the form

$$
\frac{\theta}{i}=\frac{K_{t} K_{a}^{-1}\left(1-\left(K_{m} / K_{a}\right)\right)^{-1}}{\omega_{m}^{-2}\left(1-\frac{K_{m}}{K_{a}}\right)^{-1} s^{2}+B_{a} K_{a}^{-1}\left(1-\frac{K_{m}}{K_{a}}\right)^{-1} s+1} .
$$

One obtains second order transfer function having natural frequency slightly lower than $\omega_{m}$. The attenuation is very small and depends upon structural attenuation of the torque spring.

\section{SIMULATION MODEL}

This section presents the simulation model of torque motor, which is applied to one type of servovalves of series 770 - product of MOOG. The model is built-in the program package PSPICE.

Equations (1), (2), (3), (9) and (10) are the basis for forming the model. Note that direct electromechanical analogies [4] have been used to represent mechanical elements by the electrical equivalents. On this basis the functional simulation scheme of the torque motor shown in Fig. 5 is given. Input amplifier is modeled by a voltage controlled voltage source $E_{o}$, of internal resistance $R_{o}$. The output variables are the accomplished torque, balanced by the load moment $T_{L}(t)$, and output deflection $\theta(t)$. The equivalent stiffness is given as difference between mechanical torque stiffness $K_{a}$ and magetic elasticity $K_{m}$.

\section{THE SIMULATION RESULTS AND DISCUSSION}

This section presents the characteristic waveforms od a specific torque motor which is used in servovalves of manufacturer MOOG - series 770. Specifications for this torque motor are taken form manufacturer's catalogue:

\section{Electric data:}

resistance of each winding at $25^{\circ} \mathrm{C} \quad R_{c}=22 \Omega$, selfinductance of winding $L_{c}=0.06 \mathrm{H}$, magnetic constant $K_{m}=0.833 \mathrm{~A} / \mathrm{Wb}$, torque constant, $K_{t}=0.05 \mathrm{Nm} / \mathrm{rad}$, voltage constant $K_{b}=0.05 \mathrm{~V} / \mathrm{rad} / \mathrm{s}$.

\section{Mechanical data:}

inertial torque of armature $J=2 \times 10^{-6} \mathrm{kgm}^{2}$, elastic torsion spring constant $K_{a}=1 \ldots 4 \mathrm{Nm} / \mathrm{rad}$, and equivalent 


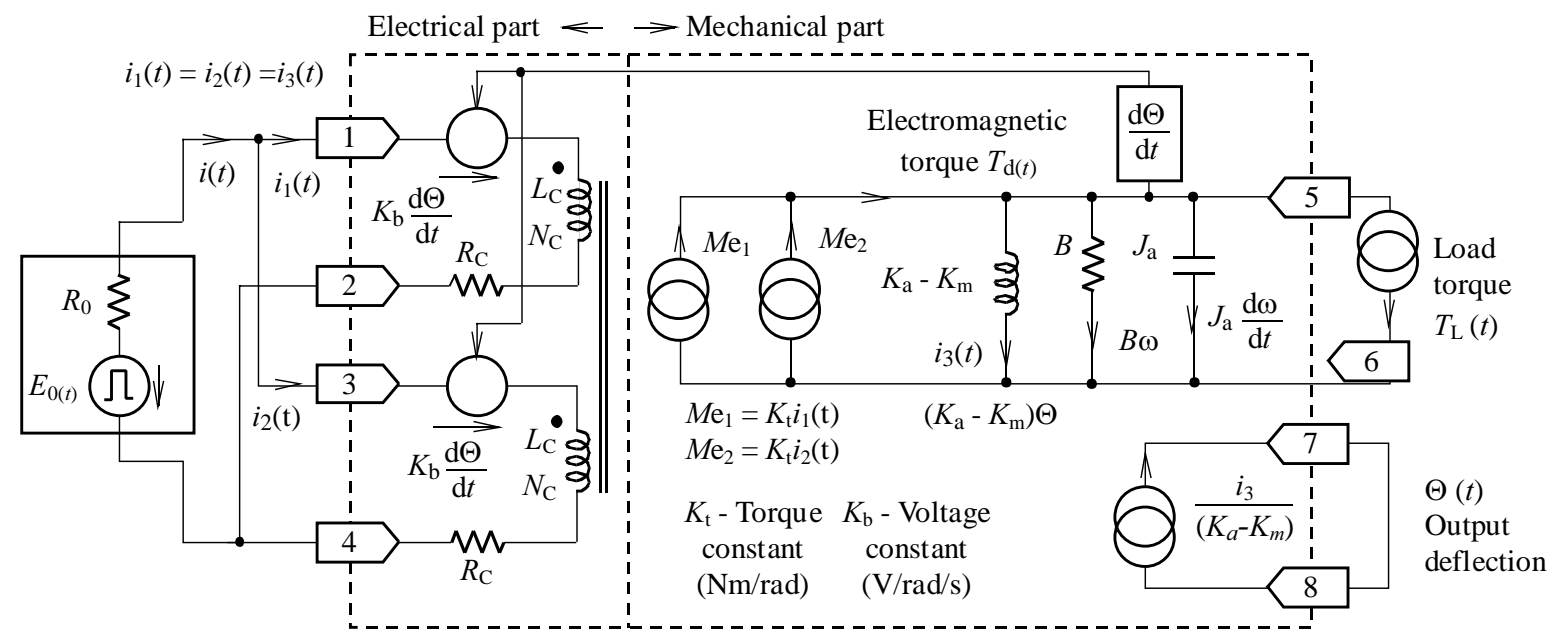

Fig. 5. The simulation scheme of torque motor

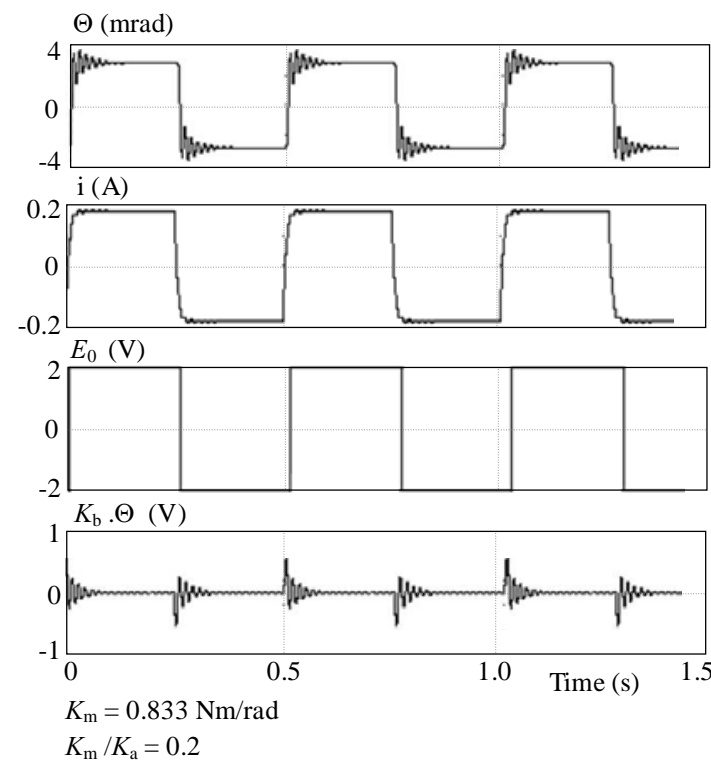

Fig. 6. Characteristic waveforms for $K_{m} / K_{a}=0.2$

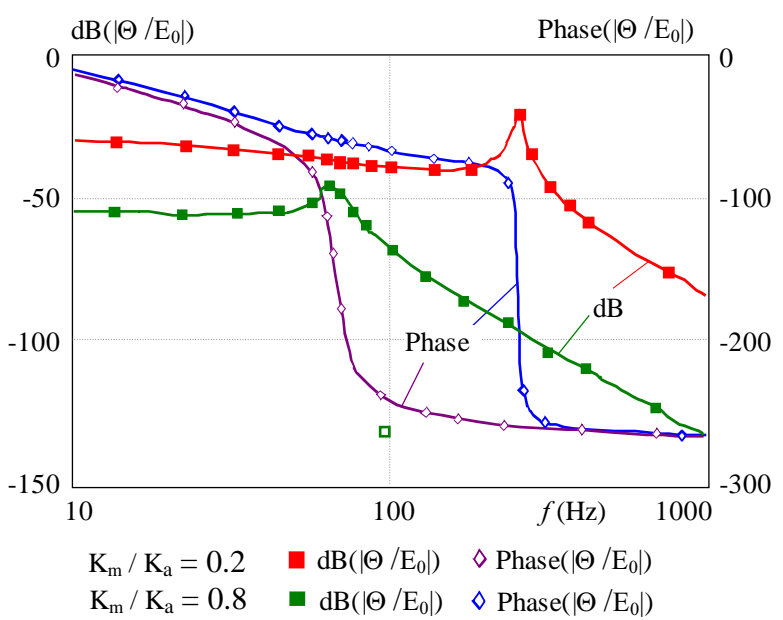

Fig. 8. Bode diagrams of the torque motor

viscous damping of the armature $B_{a}=0.0001 \mathrm{~N} / \mathrm{m} / \mathrm{s}$, radius of torque bar $a=0.02 \mathrm{~m}$.

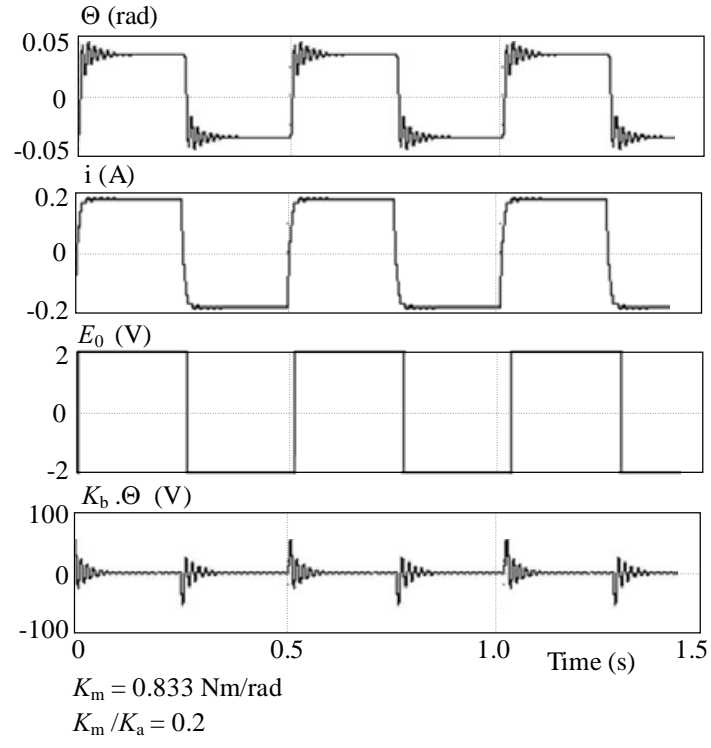

Fig. 7. Characteristic waveforms for $K_{m} / K_{a}=0.8$

Figures 6 and 7 present the characteristic waveforms in the transient regime, while Fig. 8 shows the corresponding Bode diagrams, for the cases of two boundary ratios $K_{m} / K_{a}$. The attenuation grows with the growth of this ratio. However, the static linearity and hysteresis limit this ratio, thus this parameter has to be a compromise between the two requirements. In practice, this ratio is $K_{m} / K_{a}=0.1 \ldots 0.5$.

Figure 9 shows the characteristic waveforms for the case of sinusoidal current excitation of torque motor, when $K_{m} / K_{a}=0.8$. The excitation frequency was tuned to $f_{p}=20 \mathrm{~Hz}$.

Figure 10 shows the response of deflection of the torque motor, for a pulsed load moment $T_{L}=2 \times 10^{-3} \mathrm{Nm}$, for the case $K_{m} / K_{a}=0.2$, which is usual in real situations. The restoration time is about $100 \mathrm{~ms}$, which represents a very good dynamic response. 

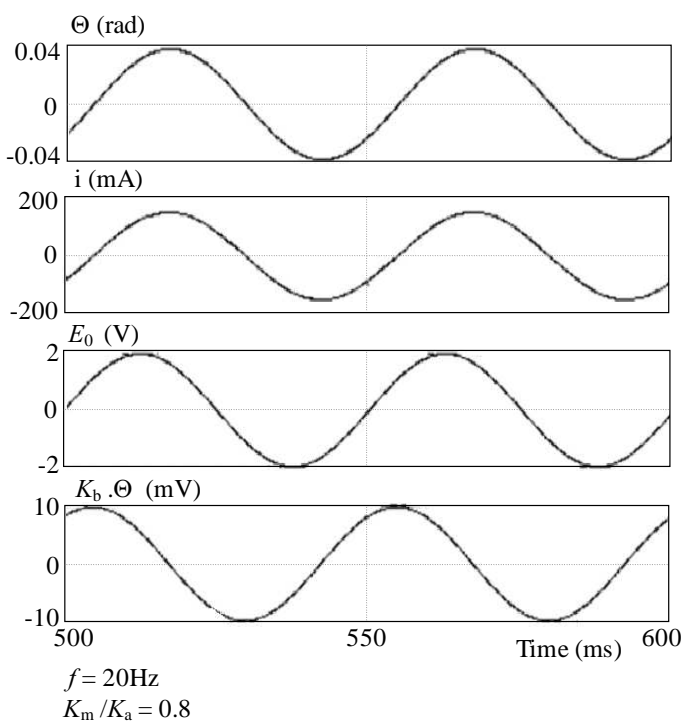

Fig. 9. Characteristic waveforms for sinusoidal excitation; $f_{p}=$ $20 \mathrm{~Hz}$

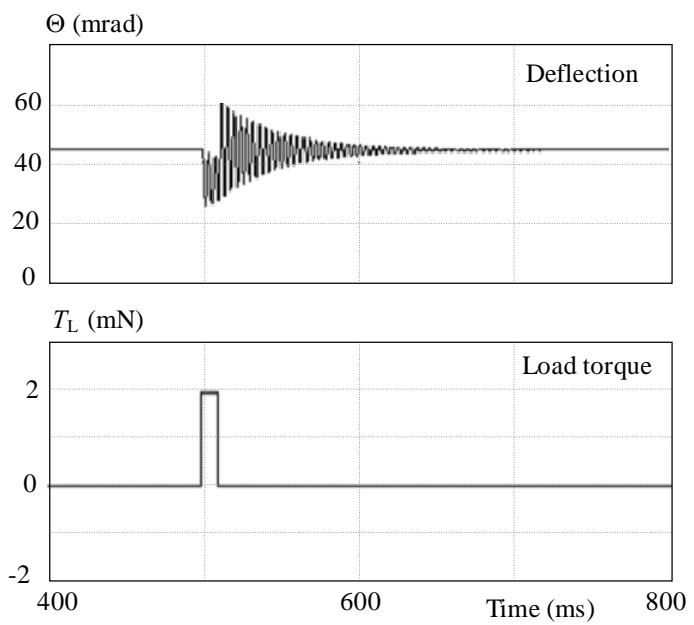

Fig. 10. Response of the torque motor for a pulsed load moment

\section{THE EXPERIMENTAL RESULTS}

This Section presents a part of the experimental results related to the electric circuit for excitation of the torque motor, shown in Fig. 1. This circuit has been realized as control part of the hydraulic pulsation module applied within the system of the testing installation used for vibrational testing. The mentioned hydraulic servovalves have been used in this system. The current of the torque motor and shift of the pilot piston have been measured for: sinusoidal excitation (Fig. 11) at excitation frequency $f_{p o b}=2 \mathrm{~Hz}$ and square-wave excitation (Fig. 12) at excitation frequency $f_{p o b}=10 \mathrm{~Hz}$.

\section{CONCLUSION}

An analysis of dynamic behaviour of the torque motor used in servohydraulic systems has been carried out. The dynamic behaviour has to a large extent been influenced by the ratio of the mechanical torque and magnetic

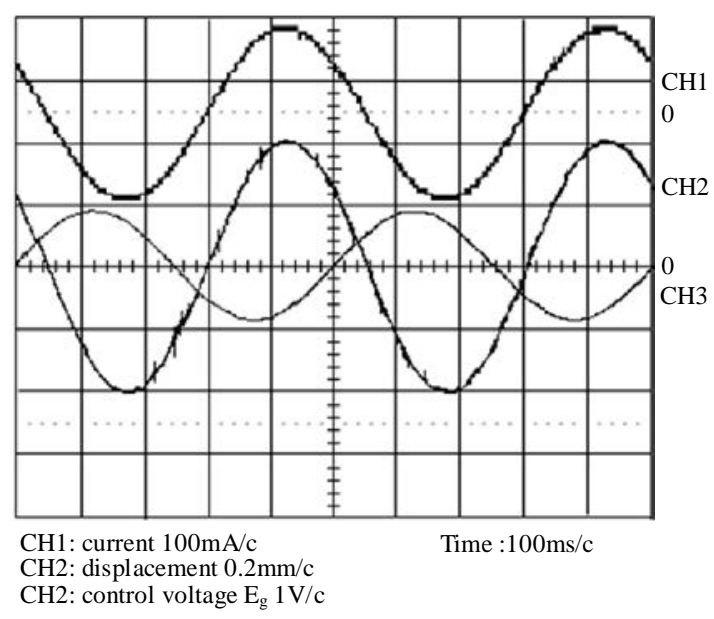

Fig. 11. Osciloscope traces at sinusoidal excitation

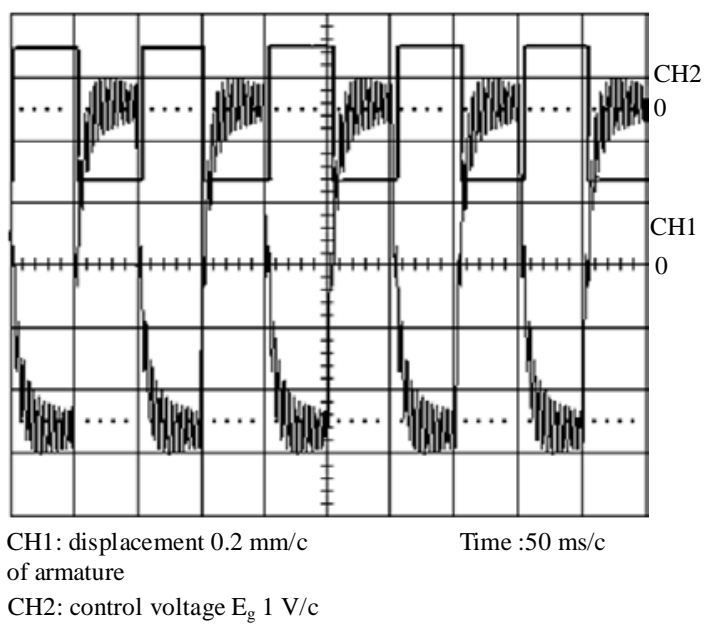

Fig. 12. Osciloscope traces at square-wave excitation

constants. The obtained analytical results have been confirmed by the simulations and experiments.

\section{REFERENCES}

[1] MERRITT, H. E.: Hydraulic Control Systems, John Willey and Sons Inc., New York, 1967.

[2] LI, S.-SONG, Y.: Dynamic Response of a Hydraulic ServoValve Torque Motor with Magnetic Fluids, Mechatronics 17 (2007), 442-447.

[3] SONGJING LIA-BAO, W. : Influence of Magnetic Fluids on the Dynamic Characteristics of a Hydraulic Servo-Valve Torque Motor, Mechanical Systems and Signal Processing 22 (2008), 1008-1015.

[4] SEELY, S.: Electromechanical Energy Conversion, McGraw Hill book, New York, 1961.

[5] CHING CHIH TSAI-SHUI-CHUN LIN-HSU-CHIH HUANG -YU-MING CHENG: Design and Control of a Brushless DC Limited-Angle Torque Motor with its Application to Fuel Control of Small-Scale Gas Turbine Engines, Mechatronics 19 No. 1 (2009), 29-41.

[6] GHASEMI, E.-JAZAYERI, S. A.-MOOSAVIAN, S. : Model Improvement for a Servovalve with Force Feedback and Back 
Pressure, Robotics, Automation and Mechatronics (RAM), Chengdu, China, Sep 2008.

[7] JinshenG, R.-XIAOYANG, L.-TONGMiN, J.-HONG, W. : Double-Nozzle Flapper-Style Hydraulic Servovalve Simulation based on Sphere Wear, Reliability, Maintainability and Safety (ICRMS), Guiyang, China, June 2011.

[8] CHENG, J.-LIU, W.-ZHANG, Z.: Modeling and Simulation for the Electro-Hydraulic Servo System based on Simulink, Consumer Electronics, Communications and Networks, (CECNet), Xianning, China, Apr 2011.

[9] URATA, E. : On the Torque Generated in a Servo Valve Torque Motor using Permanent Magnets, Proc. Inst. Mech. Eng. Part C 221 (2007), 519-525.

[10] URATA, E. : Influence of Unequal Air-Gap Thickness in Servo Valve Torque Motors, Proc. Inst. Mech. Eng. Part C 221 (2007), 1287-1297.

[11] GORDIC, D.-BABIC, M.-JOVICIC, N.-MILOVANOVIC, D. : Effects of the Variation of Torque Motor Parameters on Servovalve Performance, Journal of Mechanical Engineering 54 No. 12 (2008), 866-873.

[12] BABIC, M.-DUSAN, G.-SUSTERSIC, V.: Determination of Values for Flow Coefficients of First Stage Orifices in Two-Stage Electrohydraulic Servovalves, Heavy Machinery (HM), Kraljevo, Yugoslavia, June 2002.

[13] GORDIĆ, D.-ŠUŠTERŠIČ, V.-JOVIČIĆ, N.-BABIĆ, M. : Analysis of Servovalve Torque Motor Behaviour, Proceedings of the 29. NSS HIPNEF 2004, Vrnjačka Banja, Serbia, May 19-21, 2004, pp. 187-192. (in Serbian)

[14] GORDIĆ, D.-BABIĆ, M.-JOviČIĆ, N. : The Modelling of a Spool Position Feedback Servovalve, International Journal of Fluid Power 5 No. 1 (Mar 2004).

[15] SONGING, L-DANJ, BENZHOUX et al : 3-D Magnetic Field Analysis of Hydraulic Servo Valve Torque Motor with Magnetic Fluid [C], IEEE International Conference of Electrical Machines and Systems, Aug 21-23, 2005, Nanjing, China, 2005.
[16] ARNIM, N.-THOMAS, S.-HANNS-DIETRIH, S. et al : Ferrofluids in Electric Motors - a Numerical Process Model [J], IEEE Transactions on Magnetics 38 No. 2 (2002), 1177-1 180.

Received 6 March 2014

Željko V. Despotović was born in Prijepolje, Serbia, in 1964. He received the $\mathrm{BSc}, \mathrm{MSc}$, and $\mathrm{PhD}$ degrees from the Department of Power Converters and Drives, School of Electrical Engineering, University of Belgrade, Belgrade, Serbia, in 1990, 2003, and 2007, respectively. Since 1991, he has been with the Department of Robotics and Mechatronics, Institute Mihajlo Pupin, University of Belgrade, where he is currently at position Senior Research Associate and Senior R\&D engineer of power electronics and electrical drives. He is Associate Research Professor at the chair of Power Converters and Electrical Drives (at PhD academic study), School of Electrical Engineering, University of Belgrade, since from March 2015. He is professor at the School of Electrical and Computer Engineering of Applied Study-Belgrade, Serbia, since February 2010. His research interests include the fields of power electronics, industrial electronics, mechatronics, and vibration control. He is member of the IEEE Societies: Industrial Electronics, Industry Applications and Power Electronics.

Vladimir M. Šinik was born in Berkovići, Bosnia and Herzegovina, in 1958. He received the BSc and MSc degrees in electrical engineering from the University of Sarajevo-Bosnia and Herzegovina in 1981 and 1991 respectively. In 2001, he joined of the Technical Faculty "Mihajlo Pupin" ZrenjaninUniversity of Novi Sad, Serbia. He received the PhD degrees of the Technical Faculty "Mihajlo Pupin" Zrenjanin-University of Novi Sad, Serbia. His research interests are in Power Electronics, Power Converters, Uninterruptible Power Supply and Electromagnetic Compatibility.

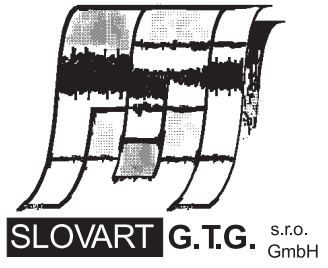

EXPORT - IMPORT
EXPORT - I M P OR T

of periodicals and of non-periodically printed matters, books and CD-ROMs

Krupinská 4 PO BOX 152, 85299 Bratislava 5, Slovakia tel: ++421 263839 472-3, fax: ++421263839485 info@slovart-gtg.sk; http://www.slovart-gtg.sk

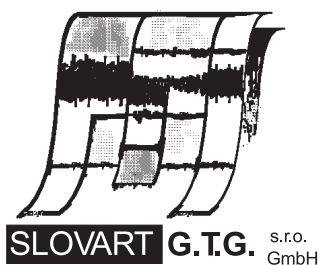

EXPORT - IMPORT 